\title{
The extent and type of gambling harms for concerned significant others : A cross-sectional population study in Finland
}

Salonen, Anne H.

2016-12

Salonen , A H , Alho , H \& Castren , S 2016 , ' The extent and type of gambling harms for concerned significant others : A cross-sectional population study in Finland ', Scandinavian Journal of Public Health , vol. 44 , no. 8 , pp. 799-804 . https://doi.org/10.1177/1403494816673529

http://hdl.handle.net/10138/229288

https://doi.org/10.1177/1403494816673529

publishedVersion

Downloaded from Helda, University of Helsinki institutional repository.

This is an electronic reprint of the original article.

This reprint may differ from the original in pagination and typographic detail.

Please cite the original version. 


\title{
The extent and type of gambling harms for concerned significant others: A cross-sectional population study in Finland
}

\author{
ANNE H. SALONEN ${ }^{1,2}$, HANNU ALHO $^{1,2} \&$ SARI CASTRÉN ${ }^{1,2}$ \\ ${ }^{1}$ National Institute for Health and Welfare, Tobacco, Gambling and Addiction Unit, Helsinki, Finland, and ${ }^{2}$ Institute of \\ Clinical Medicine, University of Helsinki, Helsinki, Finland
}

\begin{abstract}
Aims: This study investigates the proportion of concerned significant others (CSOs) of problem gamblers at population level and describes the extent and type of gambling harms for CSOs. Methods: Cross-sectional random sample data $(n=$ 4515) were collected in 2015. The data were weighted based on age, gender and residence. CSOs were identified using a question including seven options. Gambling harms were inquired using structured questions. Descriptive statistics and ChiSquared and Fischer's exact tests were used. Results: Overall, the proportion of CSOs was 19.3\%. Males had close friends with gambling problems more often than females, while females had family members with gambling problems more often than males. Of the CSOs, 59.5\% had experienced one or more harms. Females experienced more harms than males. Typical harms were worry about health or well-being of close ones, emotional distress and problems in interpersonal relationships. CSOs with a problem gambler in the family, particularly a partner, child/children or mother, experienced harms more often than CSOs with a problem gambler as a close friend. Conclusions: Female gender was associated with a larger extent of harms. The extent of harms was greatest if the problem gambler was a family member; however, a substantial amount of harms were experienced when the problem gambler was a close friend. CSOs and their position in evaluating gambling harms in general should be acknowledged. Persons beyond the nuclear family and the harms they encounter should be better acknowledged in prevention and harm minimisation. Early identification and a clear referral path to tailored support in occupational, social and healthcare settings may be considered.
\end{abstract}

Key Words: Concerned significant others, cross-sectional, gambling, gambling harm, population study

\section{Introduction}

Problem gambling and harms related to gambling activity directly affect the gambler, as well as their concerned significant others (CSOs) and society as a whole. For an effective harm-minimisation policy toward gambling, it is of utmost importance to attend to harms in a wider perspective $[1,2]$ and address gambling as a public health issue.

The estimated number of CSOs for each gambler is $10-15$ persons [3]. More recent population studies from Nordic countries report that the proportion of CSOs varies from $2 \%$ to $19.3 \%$ depending on the definition and measurement used [4-7]. Studies from Sweden [5] and Finland [6,7] used a wider approach with a lifetime frame in defining CSOs, thus finding almost every fifth participant being CSOs. The Norwegian study [4] used a family perspective and a 2 -item instrument and found $2.0 \%$ being CSOs. Based on Finnish population studies on CSOs, typically the problem gambler is a close friend $(12.4 \%-13.4 \%)$ and the proportion of CSOs with family members with gambling problems is around $6.7 \%-8.6 \%[6,7]$.

These Scandinavian studies indicate that CSOs encounter problems with health and mental health

Correspondence: Anne H. Salonen, National Institute for Health and Welfare, Tobacco, Gambling and Addiction Unit, PO Box 30, FI-00271, Helsinki, Finland. Email: anne.salonen@thl.fi

(Accepted 9 September 2016)

(C) Author(s) 2016

Reprints and permissions: sagepub.co.uk/journalsPermissions.nav

DOI: $10.1177 / 1403494816673529$

sjp.sagepub.com

(SSAGE 
[4-6], loneliness in particular for males [6], their own gambling behaviour [6], problems with other addictions $[4,6]$, risky alcohol consumption for males and daily smoking for females [6], worsening of the family's financial situation [4] and taking loans for gambling debts [5]. The Swedish study also reported that female CSOs had more sick leaves and experienced more violence compared to the general population, whereas males had more legal problems and worry about losing a job more than females [5].

Harms experienced by CSOs are multitudinous; for example, financial hardship [2,8-10], legal problems $[5,11]$, problems at work $[2,5,10,12]$, interpersonal relationship problems $[2,4,10,13,14]$, problems in family functioning including violence $[2,5,10,15]$ and stress to children $[15,16]$, perceived mental health problems $[2,6]$ and physical difficulties $[10,17]$. Further population-based research is needed to clarify the relationship between these harms and the problem gambling of a close one.

Overall, previous population-based studies on gambling problems from CSOs' perspective are scarce. To our knowledge, none of the peer-reviewed scientific articles have examined CSOs' perceptions of the extent and type of gambling harms at population level. This study investigates the proportion of CSOs of problem gamblers at population level and describes the extent and type of gambling harms for CSOs.

\section{Methods}

The data from a cross-sectional Finnish Gambling 2015 survey was used [18]. A total of 7400 Finns were randomly selected from the Population Information Registry. Inclusion criteria included: aged 15 to 74 years, mother tongue Finnish or Swedish and residing in mainland Finland. Statistics Finland collected the data using a computer-assisted telephone interview between 3 March and 8 June 2015. From the gross sample, 103 persons were not eligible. In total, 4515 interviews were completed (response rate 62\%) [18].

Finnish was mother tongue for $95 \%(n=4276)$ of the respondents, while $5 \%(n=239)$ spoke Swedish as their mother tongue [18]. Half of the respondents $(n=2247)$ were married, $36 \%(n=1637)$ were single or living in a non-registered relationship and the rest were separated, divorced or widowed. During the past year, $80 \%$ of the respondents (females $75 \%$, males $85 \%$ ) had gambled at least one game type and $24 \%$ (females $17 \%$, males $30 \%$ ) had gambled online [18]. The Finnish gambling 2015 dataset, also containing health, substance use and digital gaming related variables, will be available from the Finnish
Social Science Data Archive (http://www.fsd.uta.fi/ en/).

CSOs were evaluated by inquiring: 'Have any of the following significant others had problems with gambling?' Seven options for significant other were available: 1) father; 2) mother; 3) sister or brother; 4) grandparent(s); 5) partner; 6) own child/children; and 7) close friend. The response options were: 1) yes; and 2) no/do not know. Two more dichotomous variables were created to indicate whether the respondent had: any close ones with gambling problems (options 1-7) and any family members (options 1-6) with gambling problems.

Gambling harms for CSOs were inquired using 11 response options describing harms identified based on previous literature $[9,10,17]$ and consulting professionals in the field. Furthermore, one open-ended response option was included. First, a new variable was created to indicate the extent of experienced harms (no harms, one harm, 2-3 harms, 4-5 harms and 6 or more harms). Then, the items were used individually to describe the type of experienced harm.

The Ethics Committee of the National Institute for Health and Welfare approved the research protocol. Potential participants received written information about the study and the principles of voluntary participation.

Demographics were respondents' gender and age. The data were analysed with SPSS version 22.0 (SPSS, Chicago, IL, USA). Descriptive statistics (mean, percentages) and 95\% Confidence Intervals $(\mathrm{CI})$ were estimated. Significance $(p)$ was determined using Chi-Squared and Fisher's exact tests (Table I).

\section{Results}

A total of 4515 Finns aged 15-74 years participated in the study: $48.9 \%(n=2210)$ were females and $51.1 \%(n=2305)$ were males. The mean age of the respondents was 45.2 (95\% CI [44.7, 45.7]) years: for females 45.6 (95\% CI [44.9, 46.3]) and for males 44.8 years $(95 \%$ CI $[44.1,45.5])$.

Overall, the proportion of CSOs was $19.3 \%$ (Table I). Of all the respondents, $12.6 \%$ had a close friend who was a problem gambler, while $9.3 \%$ had a problem gambler in the family. Most typically, the family member was a sister or brother $(2.9 \%)$, the father $(2.2 \%)$, the partner $(1.8 \%)$ or own child/children $(1.7 \%)$. Males had a close friend with a gambling problem more often than females, while females had a family member with a gambling problem more often than males.

Of the CSOs, $59.5 \%$ (95\% CI [56.2, 62.8]) had experienced harms caused by problem gambling of a 
Table I. The proportion of concerned significant others and the problem gambler's relationship to the CSO.

\begin{tabular}{|c|c|c|c|c|c|c|c|}
\hline & $n$ & $\begin{array}{l}\text { All } \\
\% \pm \text { CI }\end{array}$ & $n$ & $\begin{array}{l}\text { Females } \\
n=2210 \\
\% \pm \mathrm{CI}\end{array}$ & $n$ & $\begin{array}{l}\text { Males } \\
n=2305 \\
\% \pm C I\end{array}$ & $p$ \\
\hline Any close one & 847 & $19.3 \pm 1.2$ & 416 & $19.3 \pm 1.7$ & 431 & $19.3 \pm 1.6$ & 1.000 \\
\hline Close friend & 549 & $12.6 \pm 1.0$ & 218 & $10.3 \pm 1.3$ & 331 & $15.0 \pm 1.5$ & $\leqslant .001$ \\
\hline Any family member & 411 & $9.3 \pm 0.9$ & 252 & $11.7 \pm 1.3$ & 159 & $7.0 \pm 1.0$ & $\leqslant .001$ \\
\hline Sister or brother & 128 & $2.9 \pm 0.5$ & 71 & $3.3 \pm 0.7$ & 57 & $2.5 \pm 0.6$ & .133 \\
\hline Father & 95 & $2.2 \pm 0.4$ & 56 & $2.6 \pm 0.7$ & 39 & $1.7 \pm 0.5$ & .052 \\
\hline Partner & 80 & $1.8 \pm 0.4$ & 15 & $3.0 \pm 0.7$ & 65 & $0.6 \pm 0.3$ & $\leqslant .001$ \\
\hline Own child or children & 84 & $1.7 \pm 0.4$ & 50 & $2.1 \pm 0.6$ & 34 & $1.3 \pm 0.5$ & .049 \\
\hline Grandparent(s) & 61 & $1.5 \pm 0.4$ & 38 & $1.9 \pm 0.6$ & 23 & $1.1 \pm 0.4$ & .034 \\
\hline Mother & 49 & $1.2 \pm 0.3$ & 34 & $1.7 \pm 0.5$ & 15 & $0.7 \pm 0.3$ & .002 \\
\hline
\end{tabular}

CSO: concerned significant other; $n=4515$; non-weighted: the data were weighted based on gender, age and region of residence. Significance $(p)$ was determined using Fisher's exact test; CI: 95\% Confidence Intervals.

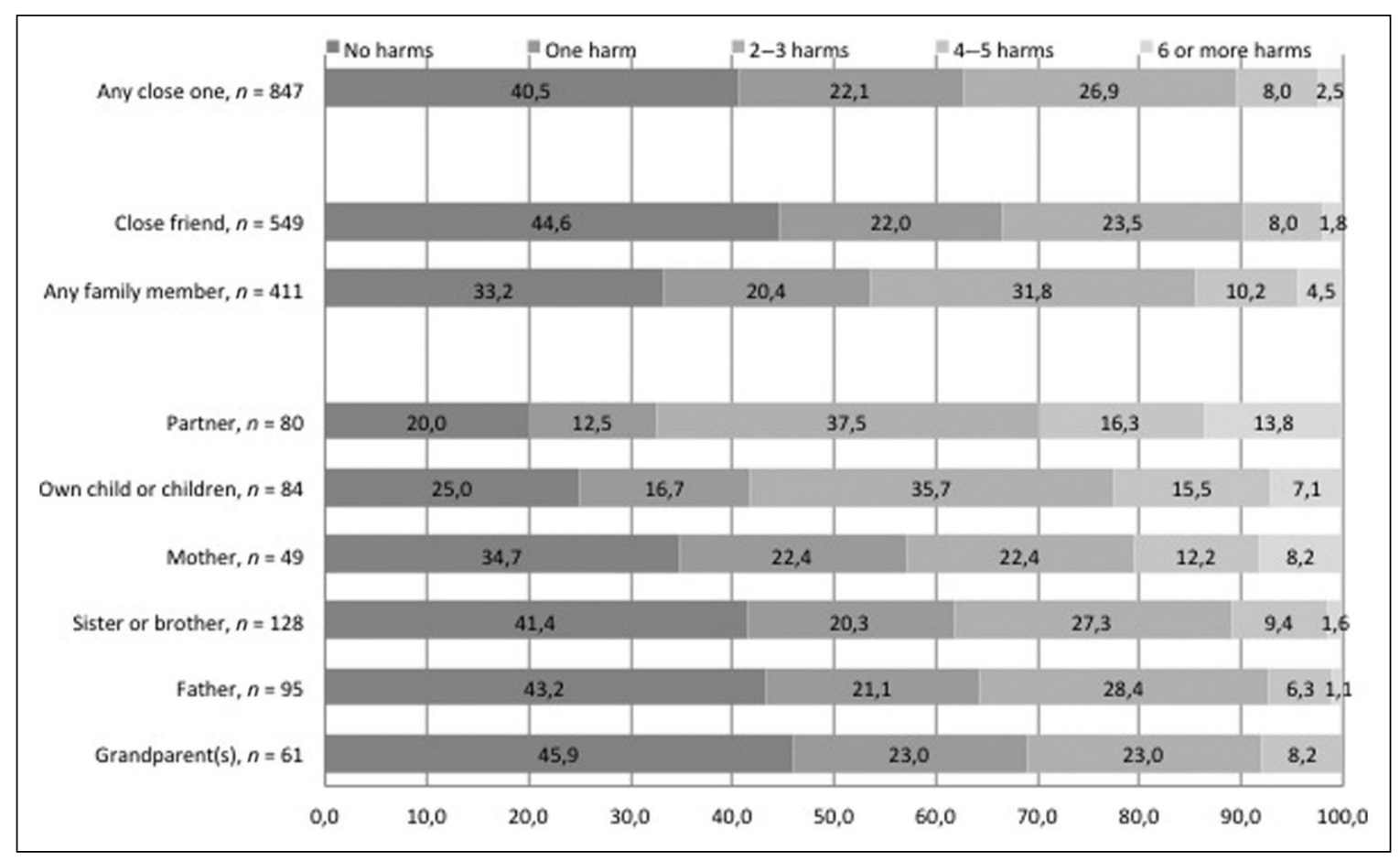

Figure 1. The extent of gambling harms for the CSOs by the problem gambler's relationship to the CSO (\%).

close one (Figure 1). If the problem gambler was a close friend, $55.4 \%$ (95\% CI [51.2, 58.6]) had experienced harms, while $66.8 \%$ (95\% CI [62.2, 71.4]) of CSOs with a problem gambler in the family had experienced harms. Most harms were experienced if the problem gambler was the partner, own child/children or mother. Females experienced more harms than males $(\mathrm{Chi}=38.258, \mathrm{df}=4, p \leqslant .001)$.

Of the CSOs, $44.3 \%$ had experienced worry about the health or well-being of their own child or other close ones, $34.6 \%$ had experienced emotional distress and $29.6 \%$ had experienced problems with either their partner or other relationships. If the problem gambler was a family member, all listed harms, except worry about health or well-being of other close ones, were more common than if the problem gambler was a close friend. Interpersonal problems were almost equally common within these subgroups. All harms, except worry about health or well-being of other close ones, were most common among CSOs with a problem gambler in the family. Other harms are listed in Table II.

\section{Discussion}

As found previously, typically the problem gambler was a close friend $[6,7]$ and almost every fifth respondent was defined as a CSO [5-7], differing 


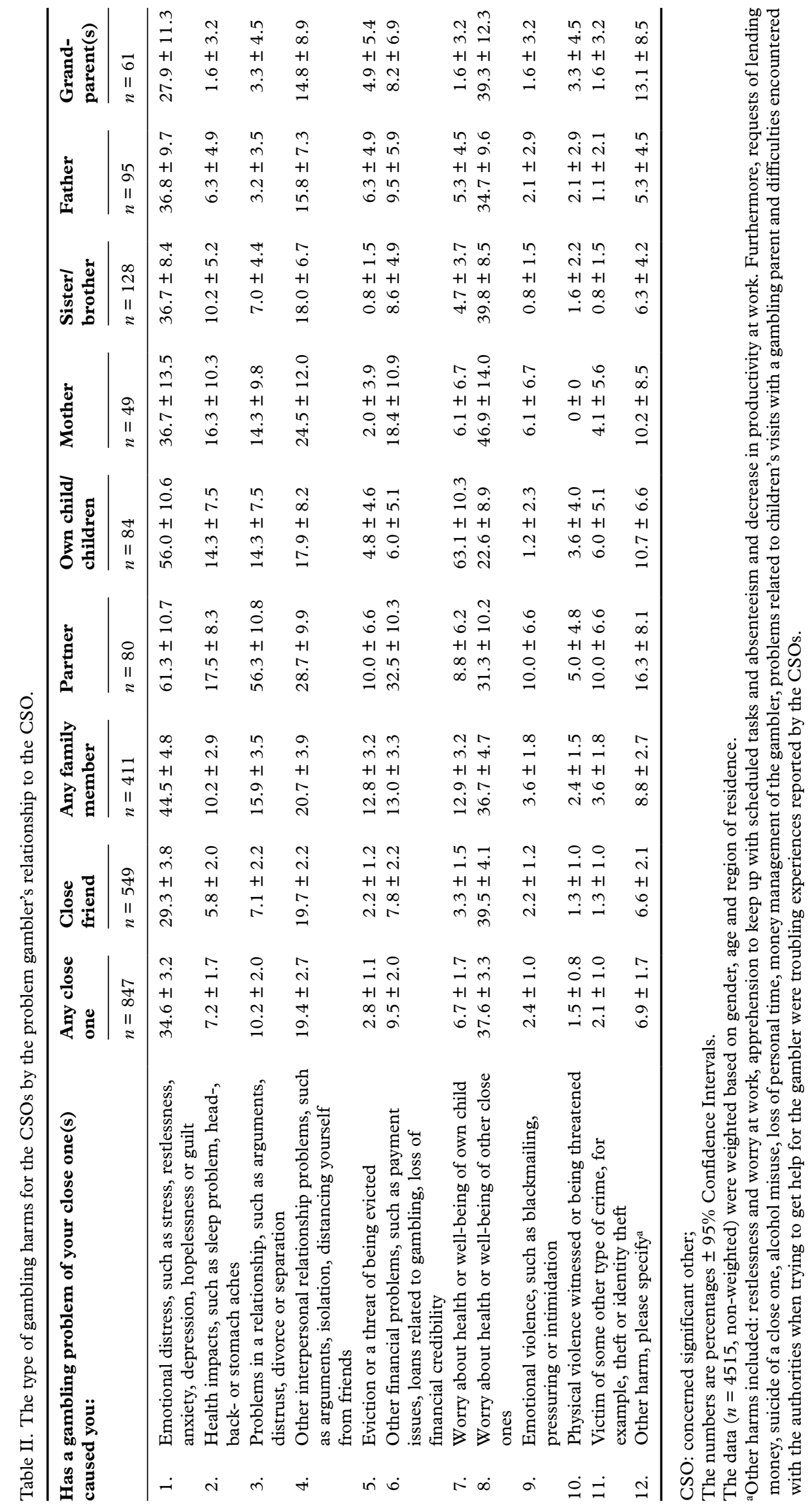


from Norwegian results with a family perspective [4]. Males had close friends with gambling problems more often than females, while females had family members with gambling problems more often than males. This indicates that different definitions for CSOs may explain the conflicting results related to gender differences in previous studies [4-6].

Most harms were experienced if the problem gambler was the partner, own child/children or mother, as reported previously [13]. However, over half $(55.4 \%)$ of CSOs with problem gamblers as a friend had also experienced harms, which confirms that problem gambling has negative consequences beyond the family [1-3].

Most common harms, worry about health or wellbeing of close ones, own emotional distress and problems in interpersonal relationships, reflect harms noticed in both population studies [4-6] and experienced by help-seeking CSOs $[4,10,13,14,19]$. The increased harms reported by CSOs, particularly in Finland, increase psychological stress and mental health problems, are a threat for family violence and stress to children [19]. However, financial hardship $[8-10]$, legal problems $[5,11]$ and family violence $[5,10,15]$ were experienced rather rarely. Herein, the problem gamblers probably include both at-risk and problem gamblers, while in the help-seeking context the Gambling Disorder [20] is encountered, which may explain the differences in the severity of harms.

Existing interventions for CSOs address the issues of enhancement of self-efficacy [21], coping skills [22] and helping gambler into treatment $[14,23]$. The early identification of possible CSOs, both within and beyond the family, would be a novel approach to prevent and minimise harms at the community level [2]. The use of, for example, the Problem Gambling Significant Other Impact Scale [24], or to ask persons who are visiting professionals in occupational, social and healthcare settings about gambling problems among their close ones, and clear referral paths and awareness of available support $[17,25]$ and tailored CSO-specific support may be considered for all CSOs. Furthermore, while examining harms from a public health perspective, the broad spectrum of harms as described in the recently proposed conceptual framework of gambling-related harm ought to be noticed $[2,26]$.

The notable fact is that even though the response rate of this study was considerably high $(62 \%)$, response activity among younger age groups was prominently lower than among older age groups [18]. Yet, participation of males (62\%) was slightly more active than of females (61\%). Also, geographic response activity was spread evenly across Finland. Our results are limited by the use of a single-item instrument with seven options in defining CSOs, missing, for example, employers, co-workers and distant relatives [3]. A lifetime frame ('has had problems') was used while assessing the prevalence of gambling problems from the CSOs' perspective. Caution is needed while interpreting the results of family members, since the small sample sizes affect the CIs. The results examining the extent and type of harms are mainly descriptive. One should also acknowledge that some CSOs (3.7\% out of $19.3 \%)$ had several close ones with gambling problems [18]. The question from this study, 'What kind of harms has a gambling problem of your close one(s) caused for you?', tackles the important task of clarifying the harms for CSOs using a population-based sample.

\section{Conclusions}

Gender was associated with the relationship between the CSO and the problem gambler, and this relationship may explain the gender differences noticed in previous Scandinavian studies. In addition, female gender was associated with a larger extent of harms. The extent of harms was greatest when the problem gambler was from the CSO's family; however, a close friend as a gambler also caused harms. CSOs and their position in evaluating gambling harms in general should be acknowledged. Persons beyond the nuclear family and the harms they encounter should be better acknowledged in prevention and harm minimisation. Early identification approaches such as screens or direct questions and the development of clear referral paths to support services may be considered.

\section{Acknowledgements}

The authors wish to thank the Ministry of Social Affairs and Health for funding. We also want to thank Mr Matthew Grainger for his linguistic assistance.

\section{Declaration of conflicting interests}

None declared.

\section{Funding}

This work was supported by The Ministry of Social Affairs and Health, Helsinki, Finland (the $\$ 52$ Appropriation of the Lotteries Act). However, it had no role in the study design, analysis or interpretation of the results of the manuscript or any phase of the publication process.

\section{References}

[1] Gainsbury SM, Blankers M, Wilkinson C, et al. Recommendations for international gambling harm-minimisation 
guidelines: comparison with effective public health policy. $\mathcal{F}$ Gambl Stud 2014;30(4):771-788.

[2] Langham E, Thorne $\mathrm{H}$, Browne $\mathrm{M}$, et al. Understanding gambling related harm: a proposed definition, conceptual framework and taxonomy of harms. BMC Public Health 2016;16:80.

[3] Lesieur H. Costs and treatment of pathological gambling. Ann Am Acad Polit Soc Sci 1998;556:153-171.

[4] Wenzel HG, Øren A and Bakken IJ. Gambling problems in the family - a stratified probability sample study of prevalence and reported consequences. BMC Public Health 2008;8:412.

[5] Svensson J, Romild U and Shepherdson E. The concerned significant others of people with gambling problems in a national representative sample in Sweden - a 1 year followup study. BMC Public Health 2013;13:1087.

[6] Salonen $\mathrm{AH}$, Alho $\mathrm{H}$ and Castrén S. Gambling frequency, gambling problems and concerned significant others of problem gamblers in Finland: cross-sectional population studies in 2007 and 2011. Scand F Public H 2015;43(3):229-235.

[7] Salonen AH, Castrén S, Alho H, et al. Concerned significant others of people with gambling problems in Finland: a crosssectional population study. BMC Public Health 2014;14:398.

[8] Dickson-Swift V, James EL and Kippen S. The experience of living with a problem gambler: spouses and partners speak out. F Gambl Issues 2005;13:1-22.

[9] Abbott M, Bellinger M, Garrett N, et al. New Zealand 2012 national gambling study: gambling harm and problem gambling. Report for the Ministry of Health. Report no. 2, 3 July 2014. Auckland: Auckland University of Technology, Gambling and Addictions Research Centre.

[10] Dowling NA, Jackson AC, Suomi A, et al. Problem gambling and family violence: prevalence and patterns in treatmentseekers. Addict Behav 2014;23:1713-1717.

[11] Kalischuk RG, Nowatzki N, Cardwell K, et al. Problem gambling and its impact on families: a literature review. Int Gambl Stud 2006;6:31-60.

[12] Downs C and Woolrych R. Gambling and debt: the hidden impacts on family and work life. Community Work Fam 2010;13:311-328.

[13] Dowling N, Smith D and Thomas T. The family functioning of female pathological gamblers. Int $\mathcal{f}$ Ment Health Addict 2009;7:29-44.

[14] Hodgins DC, Toneatto T, Makarchuk K, et al. Minimal treatment approaches for concerned significant others of problem gamblers: a randomized controlled trial. $\mathcal{f}$ Gambl Stud 2007;23(2):215-230.
[15] Patford J. For worse, for poorer and in ill health: how women experience, understand and respond to a partner's gambling problems. Int $\mathcal{F}$ Ment Health Addict 2009;7:177-189.

[16] Darbynshire P, Oster C and Carring H. Children of parent(s) who have a gambling problem: a review of the literature and commentary on research approaches. Health Soc Care Community 2001;9(4):185-193.

[17] Hing N, Tiyce $M$, Holdsworth $L$, et al. All in the family: help-seeking by significant others of problem gamblers. Int $\mathcal{f}$ Ment Health Addiction 2013;11:396-408.

[18] Salonen AH and Raisamo S. Suomalaisten rahapelaaminen 2015. Rahapelaaminen, rahapeliongelmat ja rahapelaamiseen liittyvät asenteet ja mielipiteet 15-74-vuotiailla. [Finnish gambling 2015. Gambling, gambling problems, and attitudes and opinions on gambling among Finns aged 15-74.] Report no. 16/2015, December 2015. Helsinki: National Institute for Health and Welfare (THL).

[19] Pajula M. Peluuri vuosiraportti 2013 [Yearly report of gambling helpline Peluuri], http://www.peluuri.fi/sites/ default/files/peluuri_raportti_2013_web_korj1.pdf (2013, accessed 9 May 2016).

[20] American Psychiatric Association. Diagnostic and statistical manual of mental disorders. 5th ed. Arlington, VA: American Psychiatric Association, 2013.

[21] Copello A, Templeton L, Ordord J and Velleman R. The 5-step method: principles and practice. Drugs: Educ Prev Polic 2010;17:86-99.

[22] Rychtarik RG and McGillicuddy NB. Preliminary evaluation of a coping skills training program for those with a pathological-gambling partner. F Gambl Stud 2006;22:165-178.

[23] Makarchuk K, Hodgins DC and Peden N. Development of a brief intervention for concerned significant others of problem gamblers. Addict Disord Their Treat 2002;1:126-134.

[24] Dowling NA, Rodda SN, Lubman DI, et al. The impacts of problem gambling on concerned significant others accessing web-based counselling. Addict Behav 2014;39(8):12531257.

[25] Rodda SN, Lubman DI, Dowling NA, et al. Reasons for using web-based counselling among family and friends impacted by problem gambling. Asian $\mathcal{F}$ Gambl Issues Public Health 2013;3:1-11.

[26] Browne M, Langham E, Rawat V, et al. Assessing gamblingrelated harm in Victoria: a public health perspective, https://www.responsiblegambling.vic.gov.au/_data/assets/ pdf_file/0007/28465/Browne_assessing_gambling-related_ harm_in_Vic_Apr_2016-REPLACEMENT2.pdf (2016, accessed 5 May 2016). 